\title{
A MANUTENÇÃO DA ESPERANÇA NA SINGULARIDADE \\ DE UMA ESCRITA PLURAL
}

Izabel Margato Pontifícia Universidade Católica do Rio de Janeiro

\begin{abstract}
Nunca vos aconteceu, ao ler um livro, interromper constantemente a vossa leitura, não por desinteresse, mas, pelo contrário, por afluxo de idéias, de excitações, de associações? Numa palavra, não vos aconteceu ler levantando a cabeça?
\end{abstract}

Roland Barthes

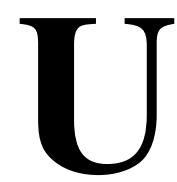

ma textualidade pronta, acabada, tal como se apresenta ao leitor, nunca se constrói no singular. Ela é sempre plural e multiplicadora. Multiplicadora enquanto texto que, a cada leitura, se desdobrará em outros textos e plural, porque na escritura de cada um subjaz o escrever de muitos. Nesse sentido, ler um texto é perceber a inter-relação existente entre escrita e leituras, entre o singular e o plural, mas é, principalmente, identificar na textualidade única de um autor a sua particular leitura das linguagens do mundo.

Saramago é um particularíssimo leitor do mundo. Se o escritor a cada momento leva o leitor a um movimento de sobressaltos motivados "por afluxos de idéias, de excitações, de associações" -, o encontro com esse particular leitor não é menos inquietante.

Como é próprio dos textos literários, os escritos por José Saramago também evidenciam o singular e o plural que habitam todos os textos. E isto não constitui novidade. Esta vai demarcar-se na maneira especial com que o autor traz esses outros textos para habitar a sua própria escritura. 
A partir das estórias que conta em cada livro, construídas com enredos desdobrados, e que parecem evoluir sempre, a cada episódio, em uma única direção (para a frente), o autor vai espalhando fios, pegadas, indícios (deixados nem um pouco ao acaso), numa disposição que aponta para outras direções : para trás, para um lado, para outro lado, enfim, para as direções necessárias ao estabelecimento de outras significações.

Muitas são as cores e formas, e múltiplos são os sentidos que caracterizam esses fios que, à primeira vista, contudo, parecem funcionar apenas como complementos ínfimos de um episódio, e não apresentar uma função significativa de maior relevo. Os exemplos seriam inúmeros: o nome de uma rua; um relógio que dá as horas; o pouco que restou de uma construção antiga; o nome dos personagens; as mudanças da natureza, enfim, os detalhes de superfície - pequenas partículas a preencher um vazio.

A esses detalhes parecem juntar-se (com maior ou menor destaque) as referências a obras de outros autores. Citações, remissões, ou simples alusões são recolhidas pelo autor e distribuídas em sua escrita, como quem cita ao acaso, ou por ouvir dizer; ou, ainda, para compor com mais um detalhe o já por mil vezes desdobrado desenho de um mosaico. Além disso, por não trazerem, em grande parte, a indicação da "antiga morada", essas citações podem passar despercebidas, sem um sentido individual, ou de remissão, que as destaque do fluxo. E, no entanto, do mesmo modo que os detalhes referidos acima, esses recortes de textos têm um relevo fundamental para a economia significativa da obra. Ao ser destacado, isto é, desligado da mera função de complemento, ou de preenchimento de vazios, o detalhe, ou o pequeno texto, irrompe como fragmento e cresce significativamente. Quando percebido como parte deslocada de um contexto anterior, o fragmento ganha a propriedade de indicar o outro - onde também está, mas disperso -, e estabelece com ele outros níveis de relações; ganha também a capacidade de significar por si, já que está desprendido e deslocado, e, ainda, ganha a possibilidade de multiplicar-se significativamente no atual espaço de relações. 
Esse poder novo de significar cabe ao leitor descobrir. Mas ele não o fará sozinho, pois na escritura tecida por José Saramago a construção desse tipo especial de discurso é proposital e, acima de tudo, tem uma função pedagógica. O autor, ao deixar fios e indícios dispersos à espera de alguém que os deslinde, deixa também pegadas, rastros de caminhos interpretativos onde, num segundo momento, será possível reuni-los e relacioná-los. É necessário estar atento aos movimentos do construtor dessa tecedura que cobre e descobre, e aponta para várias direções.

É preciso descobrir esse movimento e acolher aqui e ali outros detalhes que se desprendem, outros fios aprisionados, que depois se transformam em indícios, e seguir com eles até os lugares precisos, até os conteúdos mais ou menos definitivos para a economia significativa da obra, mais ou menos eficientes para revelar as leis desse processo de construção.

Esses eixos significativos - que muitas vezes se repetem em vários textos do autor - poderiam ser chamados, mais precisamente, de "constelação de idéias", isto é, um espaço de confluência onde se processam as novas possibilidades significativas. Cada eixo poderá acolher muitos dos vários fios que, num primeiro momento, permanecem enredados na particularidade dos casos ou camuflados na articulação das estórias. No entanto, tal como os detalhes ínfimos e as citações de outros textos, os eixos significativos de cada livro surgem dispersos nas estórias. São por elas contidos, não em relevo, mas também como indícios à espera de um leitor novo.

É necessário, então, ser um leitor novo, um leitor capaz de entender que só o seu olhar atento poderá reconhecer os diferentes níveis significativos e conhecer de perto a densidade dos fios que constroem a vasta malha do enredo, de cuja superfície apenas sobressai a paisagem colorida das estórias.

As diferentes "visões" de que fala Sérgio Paulo Rouanet ${ }^{1}$ quando analisa, a partir da teoria de W. Benjamin, as relações

${ }^{1}$ ROUANET, 1990. 
cognitivas entre o sujeito e o seu domínio dos objetos podem aqui clarificar o que denominamos "leitor novo", ou "olhar atento", como posturas fundamentais para uma leitura crítica da ficção de José Saramago. Recuperamos essa teoria por entendermos que essa ficção apresenta uma textualidade em muitos pontos semelhante à "textualidade" que nos oferece o mundo sensível.

Privilegiando a "câmara" e o "analista" como protótipos de uma certa visibilidade, Rouanet os distingue tanto da "visão desarmada", quanto da "visão filosófica":

A visão desarmada, prisioneira do fluxo dos fenômenos, é incapaz de aceder a um segundo nível de realidade, atrás da pura facticidade do que é visto. Para ela, a realidade psíquica é tão opaca quanto a paisagem urbana. (...) Por outro lado, a visão filosófica dissolve o sensível no inteligível, e o particular num universo abstrato. ${ }^{2}$

Opondo-se a estas redutoras visões, estariam a "visão da câmara" e a "visão do analista" que, antes de tudo, são atentas aos objetos. Como o "olhar desarmado", estas visões podem perceber o mundo na superfície de sua facticidade e, do mesmo modo que o "olhar filosófico", elas sabem que "a realidade não se esgota no que é oferecido imediatamente ao olhar". No entanto, elas superam esses tipos de apreensão, pois

O analista recolhe do fluxo do que é dito o fragmento que de outra forma se perderia, e o transforma em indício. A câmara mergulha tão profundamente no objeto que percebe o que nele não é perceptível, e sem sair dele, capta dimensões que o transcendem. ${ }^{3}$

Como o portador do "olhar desarmado" e pouco atento, que se deixa levar pelos caminhos da superfície; ou, como o que possui um "olhar filosófico" e, no seu modo de indagar o mundo, recolhe apenas o necessário à sua prática de construção dos sentidos, os

${ }^{2}$ ROUANET, 1990, p.12.

${ }^{3}$ ROUANET, 1990, p.12. 
leitores de José Saramago também podem processar suas leituras captando apenas o que, no geral, as estórias revelam. Ou, ainda, optar por uma leitura que seja apenas a da fruição do prazer que se revela no acompanhamento das estórias e casos que progridem num continuum de episódios. E não será pouco esse prazer. Os textos de José Saramago, além de outros atributos, possuem também, e em relevo, a capacidade de proporcionar a leitura com prazer, a leitura apaixonada, mesmo quando restrita aos conteúdos de superfície.

Mas os textos desse autor possuem outras propriedades além dessa qualidade. Os seus textos inquietam, pode-se até mesmo dizer que são textos inquietos, que não se encerram após a leitura da última página. Pelo contrário, aliás. É após a leitura dessa página que o movimento de cada texto ganha maior força e invade o leitor de uma outra maneira. E esse movimento é precioso, pois transforma o leitor comum em um outro produtor de sentidos. É aqui, então, que o olhar de câmara e de analista são chamados para o processamento de uma leitura nova, leitura que, ao procurar responder aos apelos do texto, cresce também em prazer e paixão.

José Saramago não desconhece que seus textos possuem essa propriedade aliciante, responsável por envolvimentos renovados. Antes busca reforçá-la, pois não escreve apenas por prazer, ou apenas para o prazer. Os seus propósitos são claros. Eles estão em suas declarações à imprensa, estão nos romances que escreve e estão, principalmente, na forma original como constrói a textualidade desses romances. Isto é: na forma como, através da literatura, recupera e apresenta a particular leitura que faz das diferentes linguagens com que o mundo se lhe apresenta, para com ela elaborar a sua "invenção do presente".

${ }^{4}$ SARAMAGO, 1989, p. 45. 


\section{A esperança em cena de linguagem}

Um presente assim inventado, sobre os dados novos ou renovados do passado, orientar-nos-ia, penso, para um futuro quiçá diferente do que parece prometer-nos este momento em que vivemos. ${ }^{5}$

Essa outra epígrafe fala de esperança. Embora ausente do manifesto desenrolar do texto, esse sentido vai produzir-se na interação significativa que o combinar das palavras propicia. E esse apresentar-se de forma sutil não diminui em importância o valor desse sentido no próprio conteúdo da frase. Está em relevo o valor que aqui se confere à esperança. Por outro lado, a palavra esperança não pode ser entendida, em se tratando da obra de José Saramago, como mais um conceito escolhido para se comentarem os textos do autor, ou apenas como um outro sentido relacionado à sua produção literária. A esperança, em sua obra, é um valor maior e um dos seus eixos significativos mais importantes.

É bem verdade que em alguns de seus textos, o conceito de esperança aparece relacionado ao conceito de "vontade". Há momentos até em que o autor chega a dizer que o possuir apenas a esperança é ter muito pouco e, com isso, não se chegar a nada. Mas o que estamos pretendendo neste momento, é o desenvolvimento de uma reflexão paralela à desenvolvida por W. Benjamin em relação à esperança. Nesse sentido, o termo não pode aqui ser entendido como uma espécie de sentimento desligado de uma ação e sim, como aquele que aliado à vontade, poderá produzir a própria transformação de que falam os dois autores.

Se nos indagarmos sobre o "para quê" escreve o autor; sobre o "para quê" "reconstrói o passado" como condição primeira de sua "invenção do presente", a resposta que imediatamente encontramos para estas demandas fala de esperança; a resposta que quase sempre

${ }^{5}$ SARAMAGO, 1989, p. 45. 
nos chega traz a esperança. Os recortes que destacamos abaixo podem comprovar esta constatação:

Não desista, continue a vir a Lisboa (...) mesmo que deixe de acreditar na cura, Já não acredito, Defenda o que lhe resta, acreditar será o seu álibi, Para quê, Para manter a esperança, Qual, A esperança, só a esperança, nada mais, chega-se a um ponto em que não há mais nada senão ela, é então que descobrimos que ainda temos tudo. ${ }^{6}$

....até parece que estamos a contar a história doutro país, bastou ter-se metido um terramoto pelo meio, e aí temos o resultado, quem nos viu e quem nos vê, se melhor ou pior, depende de estar vivo e ter viva a esperança. ${ }^{7}$

Nestes trechos esperança e vida quase estão confundidas, podendo, talvez, uma ser a conseqüência da outra. Por outro lado, o próprio conteúdo, que os seus romances evidenciam como um todo, fala muito de perto de uma postura que é a própria manutenção da esperança, ou do desejo de sua recuperação.

Poderíamos agora arriscar uma primeira afirmação conclusiva e dizer que o autor escreve porque, estando vivo, mantém uma esperança, ou então, que escreve para manter viva a esperança que dá sentido à vida. Esta última hipótese vai interligar-se às duas outras questões : o "porquê" e o "como" constrói o autor as suas produções literárias. E agora, quando nos indagamos sobre a finalidade de tal empresa, a resposta que encontramos nos informa que o autor, com sua produção literária, inventa o presente, através de uma reinvenção do passado, para fazer viver a esperança ou para, com ela, poder orientar-se em um futuro que não a exclua.

Em muitas das proposições de José Saramago encontramos pontos de contato com alguns dos pressupostos teóricos de W. Benjamin. Em relação a esse tópico em análise, a semelhança entre os dois pontos de vista é flagrante.

${ }^{6}$ SARAMAGO, 1985b, p.131.

7 SARAMAGO, 1985b, p. 43. 
Para Benjamin, uma das principais funções do escritor consciente é a recuperação da esperança, escondida ou "soterrada" nos discursos que, pela ótica do dominador, organizam o mundo. Essa questão é particularmente analisada em suas teses sobre o conceito de história. Na tese de número 6 Benjamin afirma:

O dom de despertar no passado as centelhas da esperança é privilégio exclusivo do historiador convencido de que também os mortos não estarão em segurança se o inimigo vencer. E esse inimigo não tem cessado de vencer. ${ }^{8}$

Não seria novidade apontar a força revolucionária dos conteúdos da teoria proposta por Benjamin, quer em relação à obra de arte, quer para a historiografia, ou ainda sobre os bens culturais. Entretanto, chama a atenção o lugar em relevo com que os seus textos expressam o desejo apaixonado de transformação do mundo. Leandro Konder comenta esse aspecto quando afirma:

O marxismo, que ele assimilou a seu modo e em termos extremamente peculiares, combinou-se com a consciência prévia, que ele tinha, de que era preciso alimentar a esperança de que um mundo bem melhor podia ser criado. Mesmo quando ainda ignorava Marx e não dispunha de razões articuladas para ativar essa esperança, Benjamin - em 1922 - já tinha uma razão prática suficiente para acreditar: encontrava-a na mera constatação de que existem seres humanos, explorados e oprimidos, nos quais o sofrimento já matou até a capacidade de eles esperarem um futuro animador. A frase com que encerra seu ensaio sobre as Afinidades Eletivas (de Goethe) expressa essa convicção: "A esperança só nos é dada por consideração àqueles que não têm mais esperança".?

Pelo menos nos pontos principais, evidenciados pela passagem citada, a afinidade entre os autores é evidente. Do mesmo modo que Saramago deixa claro que as possibilidades do futuro estariam entranhadas num passado por reinventar e que essas possibilidades têm muito que ver com um constante recuperar da esperança, Benjamin afirma em suas proposições sobre a história que,

${ }^{8}$ BENJAMIN, 1987, p. 224.

${ }^{9}$ KONDER, 1988, p.11-12. 
... a imagem da felicidade está indissoluvelmente ligada à da salvação. O mesmo ocorre com a imagem do passado, que a história transforma em coisa sua. O passado traz consigo um índice misterioso, que o impele à redenção. Pois não somos tocados por um sopro do ar que foi respirado antes? Não existem nas vozes que escutamos, ecos de vozes que emudeceram? (...) Se assim é, existe um encontro secreto, marcado entre as gerações precedentes e a nossa. Alguém na terra está à nossa espera. ${ }^{10}$

Leitor de Benjamin, Flávio Kothe, no comentário a esses postulados, afirma que a verdadeira tarefa de um olhar crítico sobre o passado seria aquela capaz de fazer "ressurgir a esperança soterrada no passado e denunciar aquilo que a estrangulara". ${ }^{11}$

Para que essas proposições fiquem mais evidentes, remetemos para a tese de número 9, de W. Benjamin, do seu "Para o conceito de história", onde propõe uma decifração ao quadro Angelus Novus.

Há um quadro de Klee que se chama Angelus Novus. Representa um anjo que parece querer afastar-se de algo que ele encara fixamente. Seus olhos estão escancarados, sua boca dilatada, suas asas abertas. O anjo da história deve ter esse aspecto. Seu rosto está dirigido para o passado, onde nós vemos uma cadeia de acontecimentos, ele vê uma catástrofe única, que acumula incansavelmente ruína sobre ruína e as dispersa a nossos pés. Ele gostaria de deter-se para acordar os mortos e juntar os fragmentos. Mas uma tempestade sopra do paraíso e prende-se em suas asas com tanta força que ele não pode mais fechá-las. Essa tempestade o impele irresistivelmente para o futuro, ao qual ele vira as costas, enquanto o amontoado de ruínas cresce até o céu. Essa tempestade é o que chamamos progresso. ${ }^{12}$

O anjo que olha para o passado é impelido, ou empurrado para a frente, por forças que não consegue evitar. No entanto, o seu olhar não deixa de fixar o passado, ou melhor, está preso a ele. Segundo Benjamin, esse seria o olhar do "anjo da história”, voltado

${ }^{10}$ BENJAMIN, 1987, p. 223.

${ }^{11}$ KOTHE, 1976, p.100.

${ }^{12}$ BENJAMIN, 1987, p. 226. 
para o passado, mas distanciando-se dele, cada vez mais, em direção ao futuro, porque arrastado por uma força que, como uma tempestade, produz seu movimento imperioso. Ora, esse olhar não poderá "fazer ressurgir a esperança" que todo o passado encerra, principalmente, porque não basta "olhar o passado" se a força que produz o movimento atender apenas às necessidades apressadas do que ele chamou "progresso".

De acordo com Benjamin (e agora segundo a perspectiva de interpretação proposta por Leandro Konder), uma das possibilidades para se construir um discurso que potencialize a esperança (e com ela alimentar as forças geradoras de transformações ou mudanças) seria, então, aquela que, pela "rememoração", recuperasse as esperanças que não puderam concretizar-se; as esperanças não vingadas que, enquanto existiam, marcaram-se apenas como a iluminação fugaz de um sonho, ou como o frágil movimento de um desejo contido. O rememorar desses sonhos e desejos seria, por assim dizer, uma possibilidade de salvação de suas "verdades" soterradas:

A "rememoração" é impotente para nos libertar dos grilhões do presente (só a revolução pode fazê-lo), porém desempenha um papel fundamental no resgate libertador do que aconteceu, do que poderia ter acontecido. Benjamin se preocupava com o efetivo aproveitamento de toda a riqueza das experiências humanas do passado, em função das necessidades das lutas que travamos no presente. Os oprimidos de hoje só terão ânimo para combater se reassimilarem as aspirações e os anseios dos oprimidos de ontem. O que os seres humanos quiseram e não obtiveram talvez possa ser alcançado um dia. E, para que a vitória venha a ser conseguida, precisamos resgatar tudo: não só o que foi dito e feito, mas também o que foi sonhado, o que foi desejado e ficou reprimido. ${ }^{13}$

Se compararmos estes últimos trechos citados com o artigo "Sobre a invenção do presente", de Saramago, não há dúvida de que

${ }^{13}$ KONDER, 1988, p. 82-83. 
os dois autores se aproximam no desenvolvimento das questões propostas, principalmente, no movimento, professado por ambos, no sentido de transformação do mundo. Ambos olham o passado como possibilidade de "reinvenções" e sabem que a partir dessa retomada se poderá construir um presente mais conforme com o que cada um espera do futuro.

Tal como Saramago, Benjamin examina o discurso produzido pela historiografia e conclui que a "redenção" do passado só será possível ao cronista "que narra os acontecimentos, sem distinguir entre os grandes e os pequenos, [e que] leva em conta a verdade de que nada do que um dia aconteceu pode ser considerado perdido para a história”. ${ }^{14}$

As proposições de W. Benjamin estão orientadas, principalmente, para a produção historiográfica. É para o "historiador materialista" que Benjamin dirige as suas teses sobre a história, ${ }^{15}$ porque apenas ele estaria apto a salvar no passado os índices de esperança, os índices de transformação que ficaram soterrados na visão parcial da historiografia que legitima o vencedor. No entanto, pelo que se depreende do exame de textos dos dois autores, acreditamos que essa tarefa não fica, pois, restrita às produções da historiografia. Outros discursos têm assumido com maior ou menor força, com mais ou menos aproximação, o desempenho de algumas das teses que Benjamin construiu em sua idealização de uma outra historiografia. A literatura é um desses discursos e, Saramago é um dos autores que vêm desenvolvendo essa aproximação.

Do mesmo modo que W. Benjamin, Saramago vê claramente a parcialidade do discurso histórico em sua apreensão do passado. Como Benjamin, chama a atenção para esse fato. Mas o que importa, agora, ressaltar não são apenas os pontos de contato, mas como o traço comum se particulariza na produção singular dos dois autores.

${ }^{14}$ BENJAMIN, 1987, p. 223.

15 BENJAMIN, 1987, p. 232. 
Se é flagrante a semelhança de conceitos a uni-los, principalmente no que se refere ao discurso da historiografia, essa aproximação adquire outra significação e desdobramento quando comparamos as seguintes constatações:

A grande dificuldade, para o historiador, está em farejar os sonhos, as aspirações, os movimentos subjetivos voltados para o porvir que não chegaram a se expressar em realidades objetivas duradouras, embora estivessem prenhes de significação histórica. ${ }^{16}$

...toda a apreensão do mundo e da vida é ficcionante, histórica para o passado, caótica para o presente, utópica para o futuro. ${ }^{17}$

No primeiro, o pensamento de W. Benjamin, atualizado pela análise de Leandro Konder, chama a atenção para os limites em que o historiador se move. Chama a atenção para a parcialidade de seu objeto e, portanto, para o quanto de um passado se perde se o recorte for marcado, tão somente, pelas "realidades objetivas". Essa "dificuldade" de que nos fala Leandro Konder deveria ser suficiente para não mais confundirmos a produção historiográfica com o discurso inquestionável, ou, dito de outra forma, com o discurso portador da verdade. A verdade que ele contém (se é possível pensar assim) é parcial. É uma verdade colhida entre muitas e apresentada de uma determinada maneira. É a sua verdade. E agora, quando paramos para pensar o segundo recorte citado, o que temos, parecenos, vem confirmar o que ficou dito acima. "Toda a apreensão do mundo e da vida é ficcionante..." Essa afirmação que numa primeira leitura parece apenas ampliar o universo do ficcional ( que não deve ser entendido como fictício) porque nele inclui toda e qualquer forma de apreensão do mundo, antes tem a função questionadora de relativizar o estatuto de "verdadeiro" que costumeiramente se atribui a alguns discursos. Não se está com isso estabelecendo uma comparação que, ao aproximar diferentes formas discursivas,

${ }^{16}$ KONDER, 1988, p. 56.

${ }^{17}$ SARAMAGO, 1989, p. 45. 
generalize ou anule as diferenças. Dizer que o discurso histórico ou científico são "apreensões ficcionantes" é reconhecer-lhes as limitações e o quanto de parcial os informa. É relativizar as suas verdades e com isso questionar o principal atributo que os distingue e eleva na hierarquia dos discursos do mundo. Dizer que esses discursos são parciais e, portanto, ficcionantes, é desconfiar da noção de objetividade a eles comumente associada. Mas não é confundi-los com a ficção. A ficção constrói-se a partir de regras próprias, "constitutivas de um universo específico"18 e, acima de tudo, não conta em seu horizonte com o conceito de verdade. Recuperar as reflexões de Luiz Costa Lima neste momento é indispensável:

O ficcional se encontra com a verdade à medida que questiona as práticas da verdade.

(...)

...à diferença do que sucede com a via da reflexão abstrata, o ficcional não tem em seu horizonte a verdade. i.e., seu trabalho não é justificado pela reiteração ou revelação de verdades novas. Significará isso dizer que o ficcional abole a questão da verdade? Absolutamente, não. Apenas se diz que sua contribuição é aí diversa da esperável quanto ao cientista e ao filósofo. ${ }^{19}$

O não possuir sob a mira o conceito de verdade não faz mais verdadeiro o discurso ficcional. Nem, tampouco, menos verdadeiro. Faz dele um outro discurso. E não é, pois, o universo do ficcional que se alarga nessa comparação entre diferentes discursos e sim a compreensão do que se tem como verdadeiro. O que é verdade no ficcional se mistura com o sonho e com o desejo, mas nem por isso carece de existência legitimada. Benjamin cobra da historiografia o exame desses objetos impalpáveis. Saramago assume esse legado com a consciência tranqüila de não estar trabalhando com "verdades menores". O seu argumento "... toda a apreensão do mundo e da vida é ficcionante..." pode ser lido, então, como uma forma

\footnotetext{
${ }^{18}$ COSTA LIMA, 1991, p. 41.

${ }^{19}$ COSTA LIMA, 1991, p. 51.
} 
consciente de bombardear, pelo menos nesse limite, as fronteiras entre discurso científico e discurso ficcional. Ao aceitar o legado preterido pelos discursos da objetividade, Saramago recupera, através de uma forma muito especial, os postulados que W. Benjamin construiu como proposta de um outro fazer histórico.

Já chamamos a atenção para o quanto de semelhança existe em algumas das opiniões expressas pelos dois escritores. Essa semelhança cresce quando comparamos os seus ensaios "Sobre a invenção do presente" e "Sobre o conceito de história". Mas também já ficou claro que a semelhança de opiniões/concepções se concretiza na diferença dos discursos que as atualizam. Saramago recupera muitos dos conceitos de Benjamin, mas os assume, insistimos, em uma forma especial: na literatura. É no espaço do ficcional que Saramago vai subtrair os conteúdos soterrados no passado para fazê-los relampejar como imagens em sua invenção do presente. É na literatura que Saramago vai "arrancar a tradição ao conformismo, que quer apoderar-se dela," ${ }^{20}$ e "escovar a história a contrapelo", ${ }^{21}$ para que os conteúdos apagados/soterrados nos desvãos, que a plumagem lisa e uniforme camufla, possam cintilar no eriçado do pelo. E é, pois, na literatura, assumindo-a, desnudando-a mesmo, como discurso ficcional, que Saramago põe num prato da balança os conteúdos até então tidos como verdade e no outro - a contradizê-la - os conteúdos que nunca tiveram peso para confrontá-la, mesmo no estatuto singular de outras verdades.

E agora o que nos importa comentar é essa singular forma de construção com a qual o autor efetiva a sua invenção do presente.

A partir de um jogo tenso e inteligente entre o documento referente em que se baseia e o seu próprio estatuto consciente de ficção, José Saramago produz o seu discurso ficcional assumindoo, antes de tudo, como uma cena de linguagem. Cena que só existe

\footnotetext{
${ }^{20}$ BENJAMIN, 1987, p. 224.

${ }^{21}$ BENJAMIN, 1987, p. 225.
} 
na e enquanto linguagem, que só existe no momento da fala, isto é, na relação leitor/autor. Cena que o autor expõe, antes de tudo, como ficção. São comuns as passagens em que o autor chama a atenção do leitor para a especificidade do texto que está lendo:

Todas as famílias têm as suas fábulas, algumas nem isso sabem, como esta dos Mau-Tempo, que bem podem agradecer ao narrador. ${ }^{22}$

São exageros do narrador,..${ }^{23}$

... em fingimento narrativo, $\ldots{ }^{24}$

Afinal de contas, isto é mesmo um conto de fadas. ${ }^{25}$

Também isto são imaginações. ${ }^{26}$

Não é possível que Blimunda tenha pensado esta subtileza, e daí, quem sabe, nós não estamos dentro das pessoas, sabemos lá o que elas pensam, andamos é a espalhar os nossos próprios pensamentos pelas cabeças alheias e depois dizemos, Blimunda pensa, Baltazar pensou, e talvez lhes tivéssemos imaginado as nossas próprias sensações ... ${ }^{27}$

Não se vá, pois, acreditar em tudo, isto é literatura. No entanto, também, são comuns as afirmações:

Olhe lá, isto é tudo verdadeiro, $\ldots{ }^{28}$

E pouco importa o referente que corresponda a esse "tudo", pois para já é linguagem, depois é literatura e, como tal, possui a sua verdade própria.

Esse "tudo verdadeiro" é, no entanto, uma verdade que resulta de um processo de dialogismo, de um processo de dispersão. É uma

\footnotetext{
22 SARAMAGO, 1985a, p. 298.

${ }^{23}$ SARAMAGO, 1985a, p. 310.

${ }^{24}$ SARAMAGO, 1985a, p. 311.

25 SARAMAGO, 1983, p. 272.

${ }^{26}$ SARAMAGO, 1985a, p. 139.

27 SARAMAGO, 1983, p. 340.

${ }^{28}$ SARAMAGO, 1985a, p. 283.
} 
verdade resultante da crença de que a verdade só pode existir no limite tenso de um diálogo com o outro. Não há aqui uma verdade única a ser apresentada. Ela não existe como mais uma questão. Ela é posta em questão. Existe, portanto, no embate, no choque, no diálogo tenso em que verdade e mentira se confrontam.

Esse processo de dialogismo constrói-se de várias maneiras. Às vezes é o próprio narrador que o instala em sua fala, negando o que antes afirmou como verdadeiro:

Não sabe por que lhe veio à idéia a passarola do padre Bartolomeu de Gusmão, primeiro não soube (...) admitiu que por sub-racional associação de idéias tivesse passado (...) para o padre voador, finalmente chegando à passarola que o imortalizou, cuja não voou nunca, mesmo que alguém tenha dito ou venha a dizer o contrário. ${ }^{29}$

Se é verdade que aqui a afirmação/negação se efetua na passagem de um romance para outro, importa ressaltar que essa particularidade não assume grande importância, pois o que o autor pretende é afirmar que a verdade de cada um dos livros só existe no presente da sua própria ficção. Mas esse presente também se movimenta em um espaço de leituras, que pode situar-se dois parágrafos acima, ou dois parágrafos abaixo. Neste caso, o jogo vai efetivar-se no presente de cada obra, atualizado em cada leitura. Ou seja, a verdade é uma ficção no presente; presente que se atualiza no mundo em movimento da ficção. O trecho seguinte é a exibição evidente desse tipo de construção:

Se a história deste caso (relação de Ricardo Reis com Marcenda) vier a ser contada um dia, não se encontrará outro testemunho, somente a carta de Ricardo Reis, se entretanto não se perder (...) Outras fontes que venham a descobrir-se serão duvidosas, por apócrifas, ainda que verossímeis, certamente não coincidentes entre si e todas com a verdade dos fatos, que ignoramos, quem sabe se, faltando-nos tudo, não teremos nós de inventar uma verdade, um diálogo com alguma coerência, um

29 SARAMAGO, 1985b, p. 339. 
Victor, um doutor-adjunto, uma manhã de chuva e vento, uma natureza compadecida, falso tudo, e verdadeiro. ${ }^{30}$

Ora, faz mesmo "levantar a cabeça" a singularidade desse discurso. É para levantar a cabeça. O diálogo "com alguma coerência”, o Víctor, o doutor-adjunto etc, etc, nos foram apresentados momentos antes, um pouco acima do parágrafo citado. Eram verdadeiros em suas falas e atos, tinham até cheiro. Mas, como o narrador nos diz : "falso tudo, e verdadeiro". É nesse limite que se inscreve a verdade do ficcional. É nesse jogo, nesse confronto, que ela se constrói. Verdade ligeira e sinuosa, verdade que é ficção. Saramago é sabedor dessa verdade. Conhece a sua singular especificidade e sabe também da sua força. Sabe como essa verdade (ao construir-se no limite entre o falso e o verdadeiro) é capaz de tocar as outras formas discursivas. E esse tocar, esse modo de confrontar, de jogar com as suas verdades, ameaçando-as mesmo, faz surgir um terceiro termo, uma outra verdade.

Em outro momento, o escritor afirma:

São os homens feitos de maneira que mesmo quando mentem dizem outra verdade, e se pelo contrário é a verdade que querem lançar da boca para fora, vai sempre com ela uma forma de mentir, mesmo não havendo o propósito. ${ }^{31}$

Saramago nesta passagem não se refere apenas à cena ficcional. Já a caracterizou como verdade na ficção. Antes, fala através dela, fala com ela. O objeto em questão, agora são os outros discursos do homem. São os discursos que os homens fazem em geral. Saramago dialoga com eles, questiona a rigidez de suas verdades, ou de suas mentiras. Com isso mina o estatuto de verdade que envolve esses discursos, e os coloca, também, na situação limite do "falso tudo, e verdadeiro." Segundo Luiz Costa Lima, é exatamente por implicar a suspensão do critério de verdade que

\footnotetext{
${ }^{30}$ SARAMAGO, 1985b, p. 198.

${ }^{31}$ SARAMAGO, 1985a, p. 284.
} 
...a ficcionalidade concede ao discurso que rege uma liberdade selvagem e ameaçadora a todo regime zeloso de sua verdade. ${ }^{32}$

Esta afirmação pode ser entendida como a segunda verdade do ficcional. A primeira é o ser ficção. A segunda seria, então, pela própria forma em que se constitui, a sua capacidade de ameaçar, e com isso relativizar, o que rigidamente se exibe como único e verdadeiro. O exame de um trecho do romance Levantado do chão pode tornar mais clara esta exposição

Que são casos verdadeiros, estes, por isso custam tanto a crer a quem se pauta por ficções. ${ }^{33}$

Aqui há uma verdade: "que são casos verdadeiros, estes." Mas é uma verdade linguageira, uma verdade-ficção. Uma verdade na ficção. No entanto, essa verdade-ficção reveste-se de outra concretude quando posta em oposição com as "ficções" que fora do discurso ficcional são vistas como verdades. O que é "pautar-se por ficções"? É o assumir como verdadeiros os discursos que como tais se apresentam, esquecendo-se até de que são discursos e, portanto, cenas de linguagem. O pautar-se por ficções é ver o mundo a partir de um discurso engendrado por uma ideologia de dominação que apresenta como únicas verdades as suas construídas ficções. E o deixar-se pautar por uma ideologia redutora implica a eliminação da desconfiança, implica a falta do olhar crítico, implica não saber que suas verdades são também ficções. Por isso custa tanto a crer que existam "casos verdadeiros" no discurso do outro, já que o assumir, como verdade, uma verdade que se quer única, significa a negação da alteridade.

Saramago desmascara esse discurso redutor. Exibe a verdade em diálogo. Leva os dois termos em tensão a um limite de interlocução tal, que deles resulta uma outra verdade. Verdade que só existe na tensão construída entre uma verdade imposta e a

32 COSTA LIMA, 1986, p. 187.

33 SARAMAGO, 1985a, p. 47. 
tentativa de substituí-la por uma outra verdade. Mas esta não será colocada nunca como única, pois ela será sempre um jogo. Saramago assume o ficcional como estatuto do literário e, com ele, expõe a ficção dos discursos redutores. Do jogo dos dois termos, vai construir um diálogo entre "verdade" e "mentira", para salvar um terceiro termo que é a invenção de uma verdade sempre outra.

Nesse sentido, Saramago assume o "não verdadeiro" do discurso literário por sabê-lo capaz de recuperar o que nos outros discursos é banido "como mentira". Por sabê-lo capaz de "farejar os sonhos, as aspirações"; capaz de resgatar o que ficou no passado apenas como esperança; capaz de libertar "do que aconteceu, o que poderia ter acontecido". E capaz de fazer verdadeiro o muito que verdadeiramente se inscreve no desejo, no sonho, na espera. O discurso ficcional é o discurso da possibilidade, mas esse possível é precioso, "por quanto o que nele está se mescla com o que poderia ter havido; o que nele há se combina com o desejo do que estivesse; e que por isso passa a haver e a estar." ${ }^{34}$

E agora depois dessas considerações, devemos retroceder ao início deste texto, para reler Barthes, para reler o fragmento que destacamos desse seu outro discurso amoroso, O rumor da língua, e para respondermos com um sim a todas as perguntas que (ali), em sintaxe portuguesa, ele nos faz.

Muito nos acontece ler "levantando a cabeça". Trabalhamos com textos literários e parece ser próprio desse tipo de discurso incitar o movimento. Mas a escolha dessa epígrafe para apresentar este escrever sobre José Saramago não foi apenas para metaforizar as muitas "excitações", as inúmeras "associações" que o seu escrever provoca. Foi também nesse sentido, mas foi, principalmente, a tentativa de sugerir (a partir de uma metáfora construída com um texto que é também o outro) a principal força organizadora da dinâmica que os textos de José Saramago provocam: o levantar a cabeça - por todos os sentidos, em todos os sentidos.

34 COSTA LIMA, 1986, p. 195. 


\section{Referências Bibliográficas}

BARTHES, Roland. O rumor da lingua. Lisboa: Edições 70, 1984.

BENJAMIN, Walter. Sobre o conceito de história. In: Obras escolbidas - Magia e técnica, arte e política. São Paulo: Brasiliense, 1987. BERMAN, Marshall. Tudo que é sólido desmancha no ar. São Paulo: Companhia das Letras, 1987.

BORGES, Jorge Luís. Ficções. Lisboa, Livros do Brasil, 1969.

BOSI, Alfredo. Fenomenologia do olhar. In: NOVAES, Adauto. (Org.).

O Olhar. São Paulo: Companhia das Letras. 1988, p.65-87.

CHAUÍ, Marilena. O que é ideologia. São Paulo: Brasiliense, 1987.

CHAUÍ, Marilena. Cultura e democracia - o discurso competente e outras falas. São Paulo: Ed. Moderna, 1982.

COSTA LIMA, Luiz. A literatura e o leitor. Rio de Janeiro: Paz e Terra, 1979.

COSTA LIMA, Luiz. Persona e discurso ficcional. In: Pensando nos trópicos. Rio de Janeiro: Rocco, 1991.

COSTA LIMA, Luiz. Sociedade e discurso ficcional. Rio de janeiro: Guanabara, 1986.

KONDER, Walter Benjamin, o marxismo da melancolia. Rio de Janeiro: Campus, 1988.

KOTHE, Flávio René. Benjamin e Adorno: confrontos. São Paulo: Ática, 1978.

KOTHE, Flávio René. Para ler Benjamin. Rio de Janeiro: Francisco Alves, 1976.

ROUANET, Sérgio Paulo. Édipo e o anjo. Rio de Janeiro: Tempo Brasileiro, 1990.

SARAMAGO, José. Levantado do chão. Lisboa: Caminho, 1985a.

SARAMAGO, José. O memorial do convento. São Paulo: Difel, 1983.

SARAMAGO, José. O ano da morte de Ricardo Reis. Lisboa: Caminho, $1985 \mathrm{~b}$.

SARAMAGO, José. Sobre a invenção do presente. Jornal de Letras, Artes e Ideas, Lisboa, 28/02/89, p. 45. 


\section{Resumo}

A particular escrita de José Saramago, construída na pluralidade de outras linguagens e a forma como esse autor, através da literatura, recupera e apresenta a particular leitura que faz das linguagens do mundo, para com ela elaborara a sua invenção do presente.

\section{Abstract}

The particular writing of Jose Saramago, constructed in the plurality of other voices. The form as this author, through literature, recoups and presents the particular reading that he makes of the languages of the world, with it elaborating its invention of the presente. 